\title{
A NOVEL SYSTEM FOR PHOTOVOLTAIC SOLAR CELL TEST AND CHARACTERISTIC MEASUREMENTS
}

\author{
Yousry Atia and Mohamed Zahran \\ Electronics Research Institute, PV Cells Dept, \\ El-Tahrir St., Dokki, 12311-Giza, Egypt \\ yousrv_atia@yahoo.com, mbazahran_2007@yahoo.com
}

\begin{abstract}
This paper describes a proposed system for testing and characteristics measurement of photovoltaic (PV) solar cells, module and/or array. The measurements are made using data acquisition system designed and implemented in the laboratory to facilitate the measuring and monitoring of the PV cells characteristics. The functioning of the software is based on the socalled virtual instrumentation. This is a non-conventional data acquisition system. The proposed system can be implemented at significantly lower cost than the commercial one. The dark characteristics test facility, based on LabVIEW software to design an easy handling Graphical User Interface (GUT) and use a single chip microcontroller with a serial interface as a data logger. The system is used to acquire the measured data from the cell under test and transfer it to a supervisory computer for monitoring and other signal processing. The system also allows the user to save the collected data for documentation. The preliminary test we have made indicates that the system proposed here is highly reliable, which allows measuring and monitoring variety of solar cell, module and/or array characteristics with a good accuracy. So it can be used in trusted manner for evaluating and documenting the PV systems.

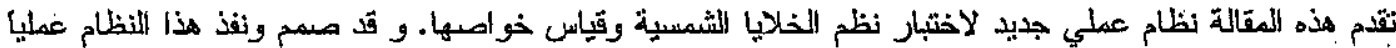

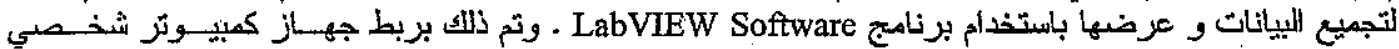

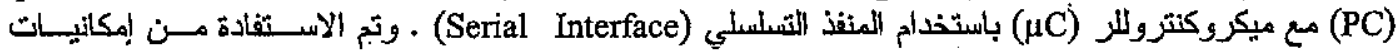

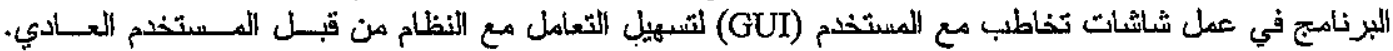

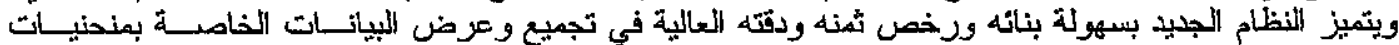

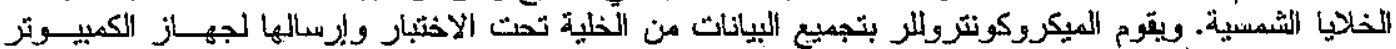

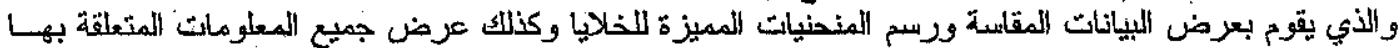

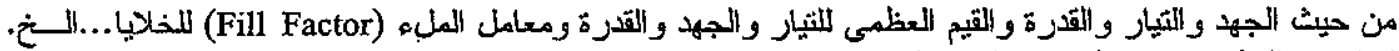

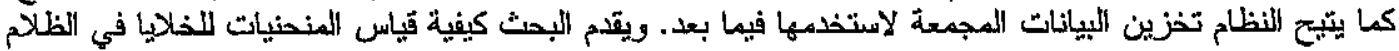

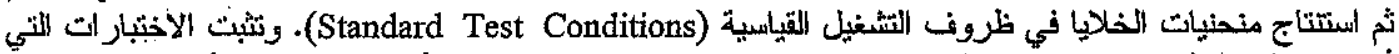

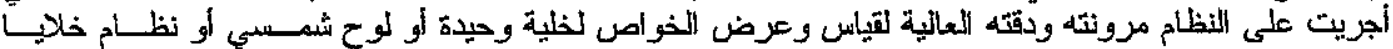
شمسية كامل والذي يمكن الاعتماد عليه في تقييم واصدار تقارير كاملة عن نظم الخلايا الشمسية.

Keywords: Solar Cells, Photovoltaic, PV characteristics measurement, I-V Curve Tracer, LabVIEW, PC-Microcontroller interfacing.
\end{abstract}

\section{INTRODUCTION}

In the photovoltaic field, manufacturers provide ratings for PV modules for conditions referred to as standard test conditions (STC). However, these conditions rarely occur outdoors, so the usefulness and applicability of the indoors' characterization in standard test conditions of PV modules are a alternative method for PV systems test. Therefore, to carry out photovoltaic engineering well, a suitable characterization of PV module electrical behaviour (I-V curves) is necessary [1].
Since solar cells convert light to electricity it might seem odd to measure the photovoltaic cells in the dark. However, dark I-V measurements are in valuable in examining the cell properties. Under illumination, small fluctuations in the light intensity add considerable amounts of noise to the system making it difficult to measure. Dark. I-V measurements use injects carriers into the circuit with electrical means rather than with light generated carriers. In most cases the two are equivalent and the dark I-V measurements give extra information about the cell for diagnostic purposes. Even in the absence of noise there is a wealth of information in 
comparing the illuminated and dark $\mathrm{ImV}$ curves [2]. The solar cell characteristics are handled in many references [3-13]. Alternatively, the static parameters and characteristics of solar cells are normally determined from their illuminated current-voltage characteristics under standard solar simulators, based on flash lamps or distributed light sources, or outdoor conditions. They are used in assessing solar cell efficiency and fill factors. On the other hand, dynamic parameters are required in designing circuits containing solar cells and switching devices as well as providing important diagnostic tools.

\section{SOLAR CELL (SC) CHARACTERISTICS}

In the characterisation of PV modules several types of methods can be differentiated. Those are able to obtain the PV module behaviour in STC. The methods obtain the characterization of the PV module in STC from outdoor measures. In these cases, a process in two stages is necessary:

First stage, the experimental measurement of $\mathrm{I}-\mathrm{V}$ characteristic along with the predominant conditions of operation, and, second, the extrapolation of the measures to STC.

In this work, the I-V characteristics of the solar cell is provided in the dark mode as a diode characteristics, then data extrapolation is made to normalize the test result curves to STC.

\section{I-V CURVE MEASUREMENTS OF SC}

\subsection{Cell Model}

A solar cell is usually represented by an equivalent one-diode model. The model contains a current source Iph and series resistance Rs, which represents the resistance inside each cell and in the connection between the cells as shown in Fig. 1. The net current is the difference between the photocurrent $I_{\text {ph }}$ and the normal diode current $I_{D}[1,2 \& 7]$;

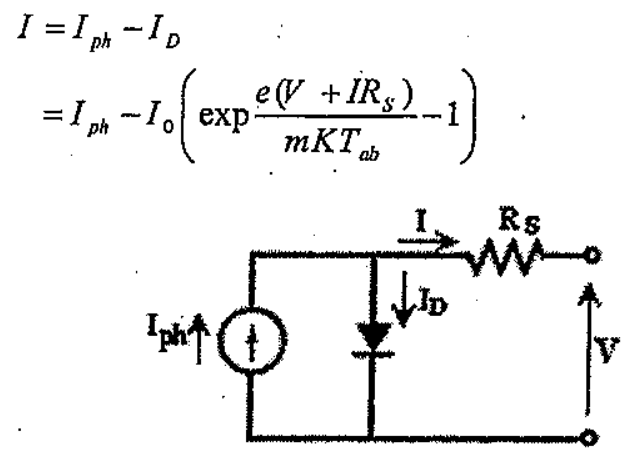

Where:

Fig. 1 Solar cell model.

$\mathrm{m}$ is the idealization factor,

$\mathrm{K}$ is the Boltzmann's constant,

$\mathrm{T}_{\mathrm{ab}}$ the absolute temperature of the cell,

e electronic charge.

$\mathrm{V}$ is the cell voltage and,
$I_{0}$. is the saturation current, which depends strongly on the cell temperature.

\subsection{System Objective}

The system was developed for measuring and monitoring a PV solar cell, module and/or array. It provides facilities to get the test through three kinds of measurements:

Environmental and system variables (ambient temperature, solar radiation, current, voltage, energy, power, etc.).

The dark I-V characteristics for the cell, module and/or array. (open circuit voltage, $\mathrm{V}_{\text {oc }}$; short circuit curxent, $I_{s c}$; fill factor, $F F$; efficiency, $\eta$ and maximum power, $P_{\max }$ ).

Forecast the I-V and P-V curves of the PV cell, module and/or array in STC or any condition as well as determination of its electric cell parameters.

The user can display in a computer screen the instantaneous values of any of the above parameters and graphs of the I versus. $V$ and $P$ versus. V curves.

\subsection{System Setup Circuit}

The proposed data acquisition system is using the microcontrollers as a data logger for measuring and acquiring the signals and transmitting it to a $\mathrm{PC}$ through serial port RS-232.

The experimental setup circuit for cell dark characteristics is shown in Fig. 2.

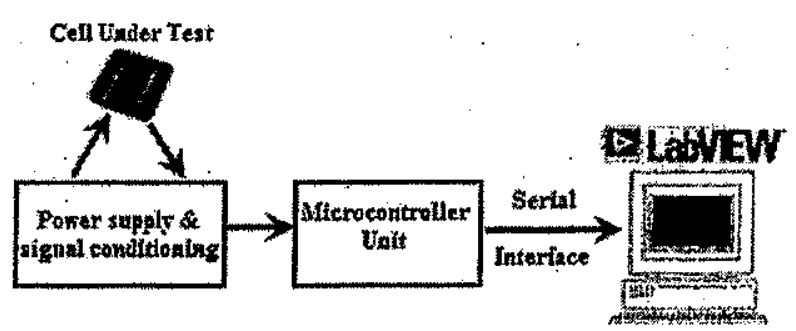

Fig. 2 Dark cell measurements setup circuit.

Usually, the data transmission through the serial port is limited when data acquisition at high sampling rates is required [14]. In our work we acquiring the data and saving it in the microcontroller S-RAM, after test is completed the data are transmitted to the $\mathrm{PC}$ via the serial port. Also this limitation does not occur when the data acquisition is performed using $\mathrm{I} / \mathrm{O}$ modular devices. Another limitation we have identified in conventional data acquisition systems is the difficulty of making any modification to the test programs. This limitation is absent where the programs are developed using LabVIEW, where the user can modify and process the collected data to minister his own objectives. Additionally, the high cost of commercial automatic data acquisition systems that are capable of monitoring and operational control of PV solar plants is the main 
limiting factor for the development of PV system projects in developing countries.

\subsection{Measurement System Description}

The dark test equipment consists of AC power supply (PS) with DC offset adjustment facility, signal conditioning circuit, AVR microcontroller and a personal computer (PC). Under dark condition, an AC signal from PS is. imposed on the cell under test, and then the resulting current and voltage signals are collected. Several current-voltage data points are obtained to generate the dark cell characteristic curve. The data are stored in the microcontroller $S$ RAM. The PC then collects the data from the microcontroller via the RS-232 serial port. The data are stored in a data file for documentation purpose, in a table and in X-Y graph for mentoring on the PC screen. These data are manipulated to obtain the illuminated electrical performance for the solar cell, module and/or system at STC or any illumination conditions.

\section{SOLAR CELL I-V TEST LabVIEW PROGRAM}

LabVIEW based GUI program virtual instrument (vi) is developed to configure the computer as supervisory monitoring system and interfaced with AVR microcontroller via RS232 serial communication. The program controls the microcontroller by ordering it to start solar cell testing, and to collect the measured data. The PC LabVIEW receives the data from the microcontroller, save it in a file, then viewing the measured points in a table, processing the received data and controlling the result graphs. The graph preview area shows the collected data points after a sweep. The voltage, current and power data are recorded in a table specified by the user. The program allows the user to configure and modify the method of data processing. These methods are the dark characteristics, or the illuminated characteristics.

\subsection{LabVIEW Program Block Diagram}

The solar cell I-V \& P-V test setup block diagram is shown in figure 3 . The block diagram can be divided into two main sections; the first section is the initialization of serial interface while the second section is responsible for measured data processing.

\subsection{LabVIEW Program Front Panel or (GUI)}

The front panel of the developed LabVIEW Program is shown in Figure 4. The measured data is presented in the front panel of LabVIEW program in two forms, table with voltage, current and power of the cell under test. The other form is the X-Y graph for I$\mathrm{V}$ and P-V. Also the other important points as $I_{S C}$, $V_{O C}$, and $P_{\max }$ are measured and presented. The initialization parameters of the serial are presented also in the front panel allowing the user to input the relevant data for his application. The output buffer (write) orders the microcontroller to start testing process then transferring data to PC. The measured data are back to the input buffer (read) that is included also in the front panel. The solar cell $\mathrm{l}-\mathrm{V} \&$ $\mathrm{P}-\mathrm{V}$ diagrams are shown in Fig. 4.

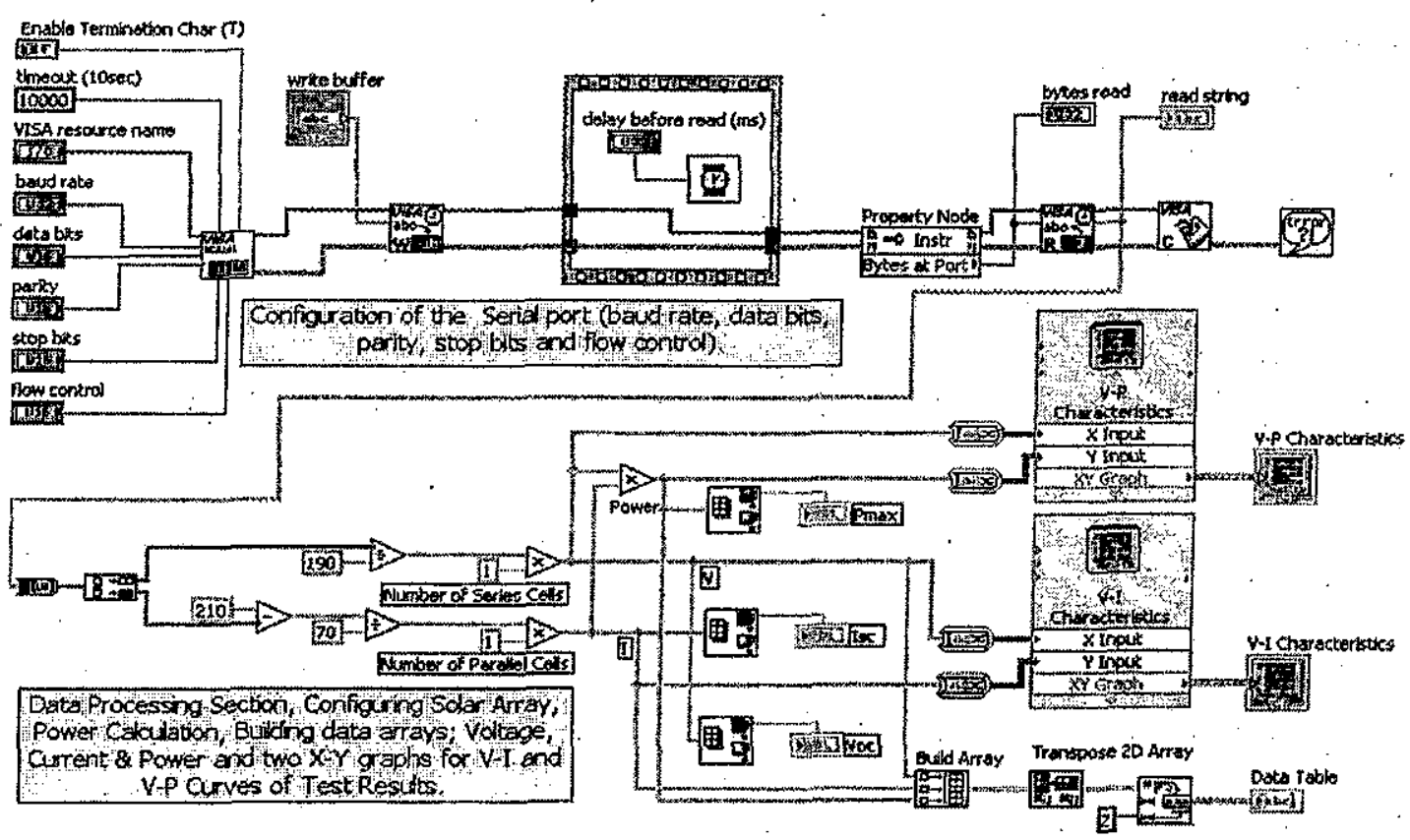

Fig. 3 LabVIEW serial interface and I-V and P-V curves measurement block diagram 


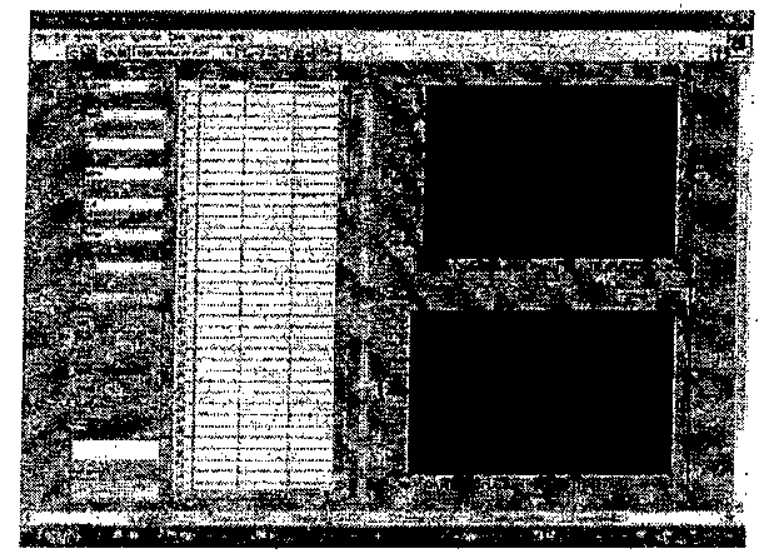

Fig. 4 LabVIEW graphical user interface menu.

\subsection{AVR ATmega16 Microcontroller}

The (AVR ATmega16) microcontroller that is used in the proposed work is a low-power, lower cost CMOS 8-bit microcontroller. It has powerful instructions in a single clock cycle, the ATmega16 approaching one MTPS (million instruction per second) per $\mathrm{MHz}$ allowing the system designer to optimize power consumption versus processing speed.

The used microcontroller has the following important features:

$0-16 \mathrm{MHz}$

32 Programmable I/O (input output) Lines

Byte-oriented Two-wire Serial Interface

8-channel, 10-bit ADC (analog to digital converter)

$16 \mathrm{~KB}$ of Self-programmable Flash memory

512 Bytes EEPROM

1K Byte Internal SRAM
The following sections illustrate the control circuit hardware and the microcontroller program. flow chart.

\subsubsection{Microcontroller Control Circuit with Serial Interface}

The proposed microcontroller control circuit is shown in Fig. 5. Serial interface is used to communicate with PC where the Graphical User Interface (GUI) is developed using the LabVIEW software package. The converter and conditioner device MAX232 chip is used to interface the microcontroller serial terminals and the PC RS232 via standard serial cable. The required power supplies, reset and crystal circuits for microcontroller operation are developed also. The microcontroller is configured where one port (port $\mathrm{C}$ ) is interfaced with (digital to analog converter) D/A device to generate the analog control signal that controls the power switch of solar array testing in illuminated mode. Port $\mathrm{A}$ is used as A/D converter; channel 0 and channel 1 are used to measure the solar array current and voltage. Serial Interface is used to communicate with PC.

\subsubsection{Microcontroller Program Flow Chart}

The microcontroller program flow chart is shown in Fig. 6. The microcontroller program starts with initialization of all microcontroller peripherals as parallel and serial ports, $\mathrm{ADC}$ channels, ..etc. The program is divided into two main phases; data measuring phase, and data transmitting phase. This technique is used to override the serial port speed limitations.

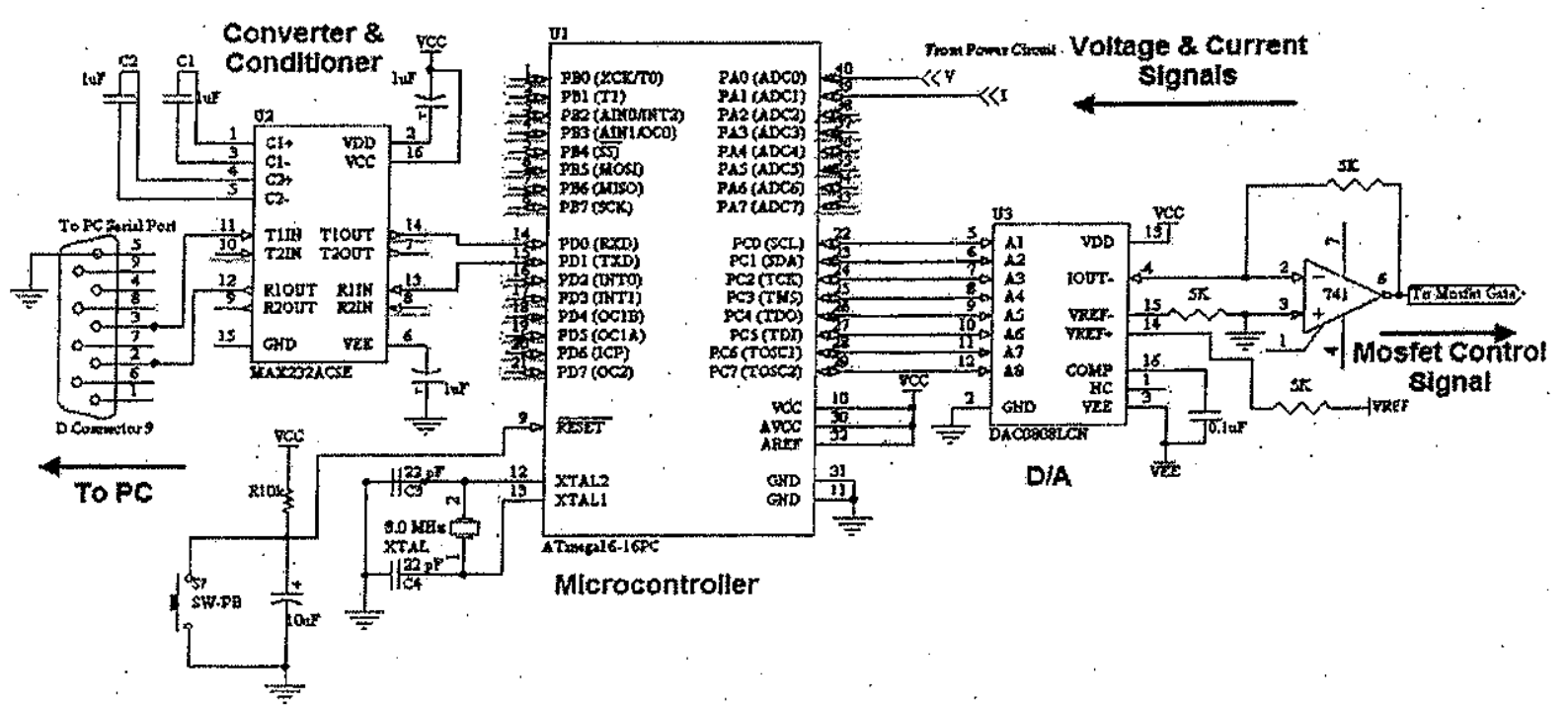

Fig. 5 The microcontroller interfacing and measurement control circuit. 


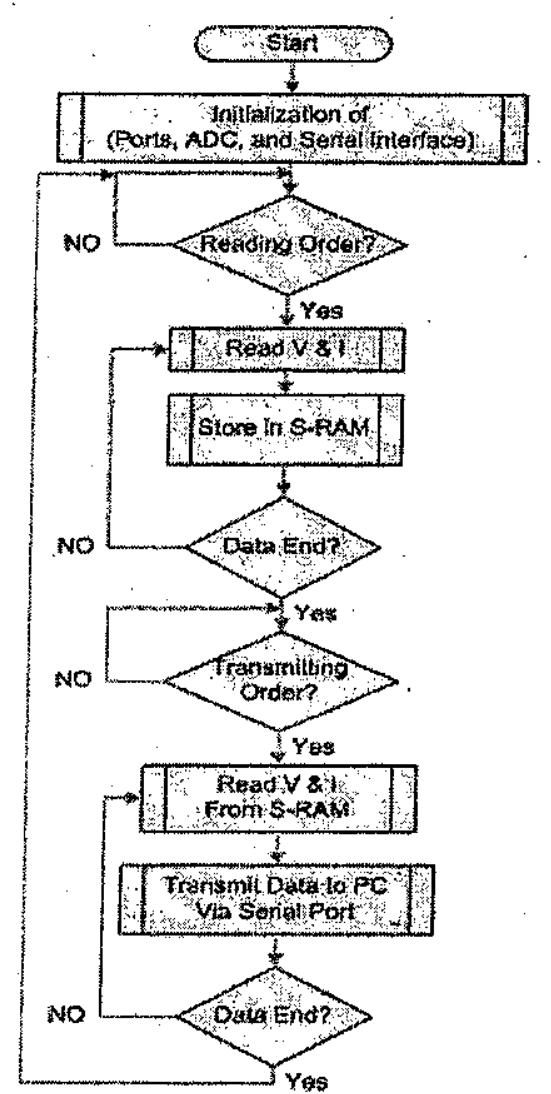

Fig. 6 Microcontroller control program flow chart.

\section{DEVELOPED EXPERIMENTAL CORCUITS}

There are two developed experimental circuits; one for dark test and the other for illuminated test.

\subsection{The Dark Test Circuit}

The dark test circuit of the single solar cell is illustrated in Fig. 7.

As the microcontroller A/D device is a unipolar, so it can't measure negative signals. DC offset signal is added to the AC signal of power supply (AC PS) then in the software it is taken into account. A signal conditioning circuit is built to read two signals (V\&I) with one common ground.

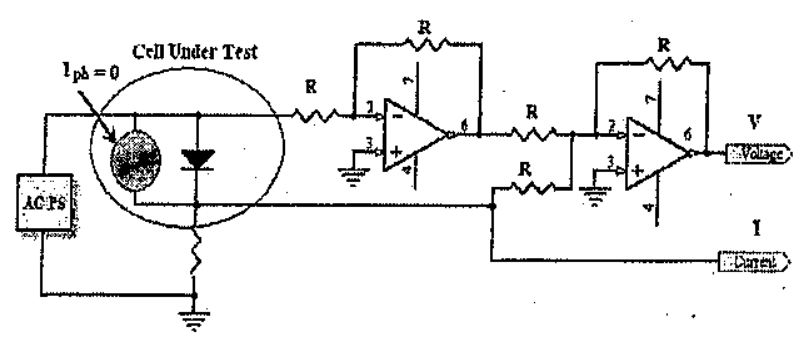

Fig. 7 Single solar cell dark test, and signal conditioning circuit.

\subsection{Illuminated Solar Array Characteristics Measurements Power Circuit}

The power circuit of the solar array or solar module testing in illumination mode is illustrated in Fig. 8. It consists of the following components:

- The solar module or solar array under test,

- A voltage transducer LV25-P type to measure the solar array terminal voltage,

- A power MOSFET that represents an electronic load to change the solar array output current from zero to short circuit value, or to the change the solar array terminal voltage from open circuit to zero value,

- A signal conditioning circuit used to isolate the control signal from microcontroller and to control the operation of the power electronic switch (MOSFET) which operated in the active region,

- A current transducer LA25-NP type to measure the solar array output current, the two output analog signal; voltage and current are wired to the input two analog channels in the AVR microcontroller.

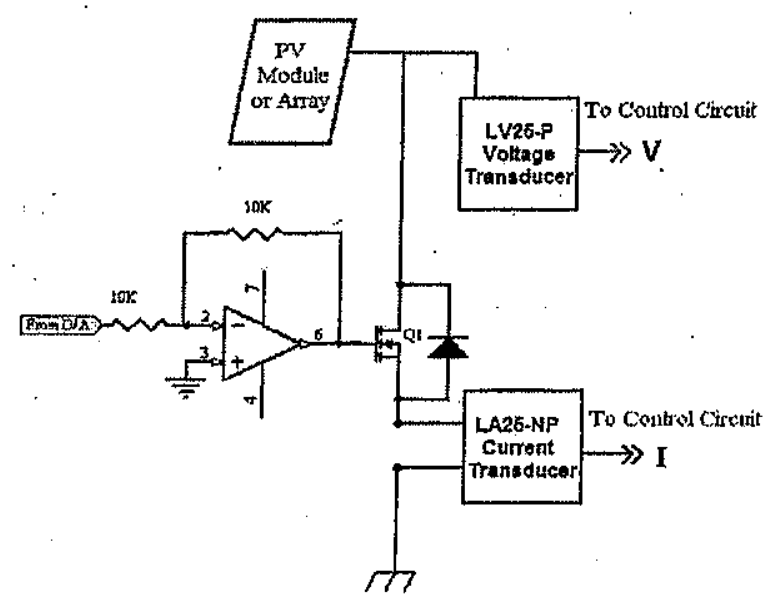

Fig. $8 \mathrm{I}-\mathrm{V}$ measurements power circuit.

\section{EXPERIMENTAL RESULTS}

The proposed system is implemented as shown in Fig. 9. The system is composed from the following components; solar cell under test, power conditioning circuit, power supply, microcontroller board and the measuring tools oscilloscope and supervisory control (Laptop Computer) with the developed program. The solar cell tests are executed in two stages. In the first stage, the system is used to measure the dark characteristics of the solar cell under test. The solar cell is mono-crystalline silicon cell with $10 \times 10 \mathrm{Cm}^{2}$. The I-V curves are measured and the results are shown on an Oscilloscope monitor as well as on the front panel of implemented GUI software. The test results are shown in the following two graphs; Fig. 10 and Fig. 12. 


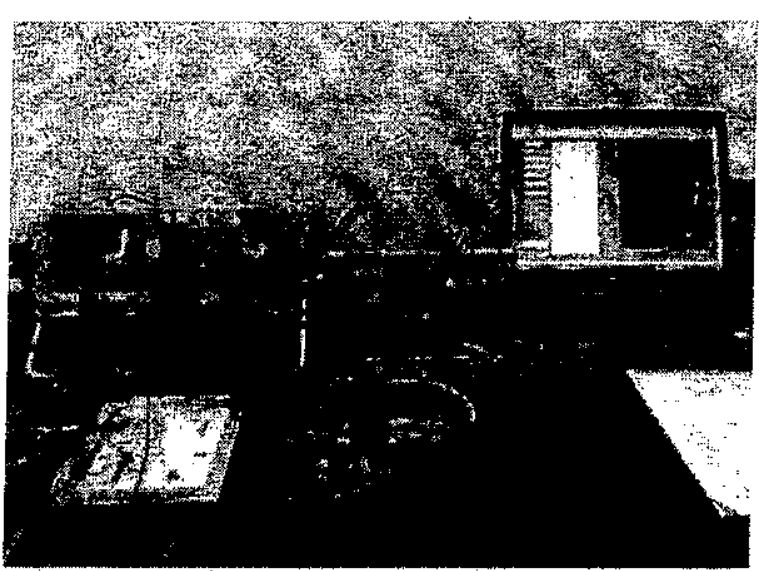

Fig. 9 Hardware setup showing I.-V on Oscilloscope and on the Laptop monitor using GUI Software.

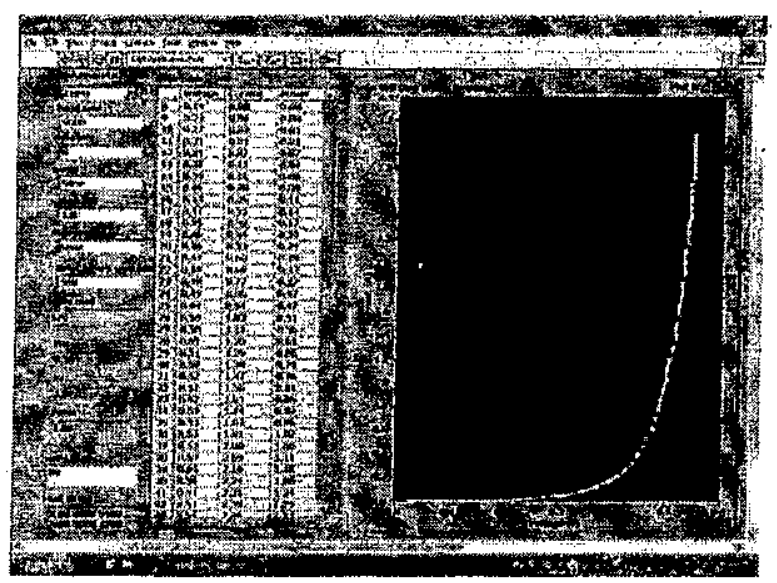

Fig. 10 The I-V curve of diode characteristics of the solar cell under test using the developed system.
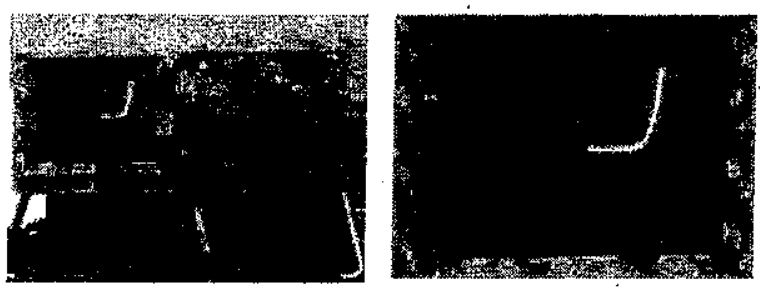

Fig. $1110 \times 10 \mathrm{~cm}^{2}$ solar cell $\mathrm{I}-\mathrm{V}$ test results, $\mathrm{X}$-axis: $0.2 \mathrm{~V} / \mathrm{div}, \mathrm{Y}$-axis $1 \mathrm{~A} / \mathrm{div}$

Comparing the two $\mathrm{I}-\mathrm{V}$ curves, it seems that they are identical by means that, the data processing in the developed LabVIEW test program is valid.

In the second stage, a data processing module were added to developed LabVIEW program block diagram to present the $\mathrm{I}-\mathrm{V}$ in the first quarter as usual form. Also, the power curve (P-V) is deduced from the measured data. Both I-V and P-V curves are presented in the GUI front panel.window. The results are shown in Fig. 12.

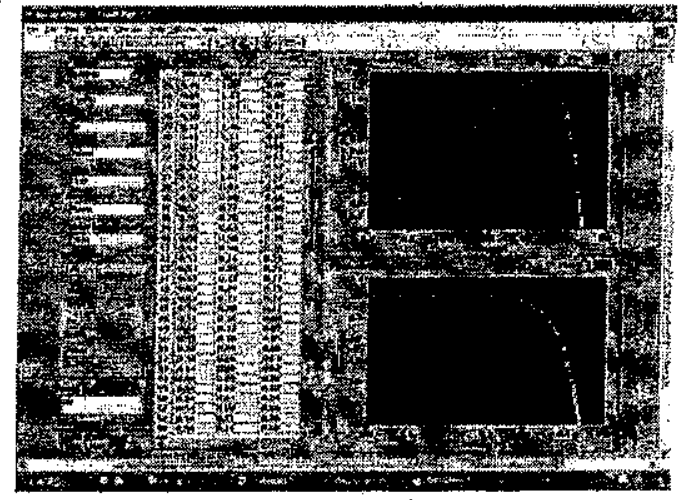

Fig. 12 LabVIEW GUI of $10 \times 10 . \mathrm{cm}^{2}$ solar cell test results; I-V \& P-V

\section{CONCLUSIONS}

A developed technique for presenting the methodology of solar cell characteristics is presented in this paper. The hardware setup of the proposed technique is illustrated in details in this paper. The AVR ATmega16 is applied and the wiring diagram of the microcontroller and all the necessary conditioning circuits are given. The flow chart of the developed microcontroller software program is given also. The power circuit of measuring the solar cell (or solar array) characteristics in both dark and illumination modes are implemented and illustrated. The LabVIEW software is applied in this work to pack and draw the collected data of solar cell characteristics from microcontroller subsystem. The complete block diagram is shown in details in this paper. A graphical user interface (front panel) is designed in the developed testing program. It is used to present the measured solar cell testing data, the packed data and the plotted $\mathrm{I}-\mathrm{V}$ and $\mathrm{P}-\mathrm{V}$ curves. A mono-crystalline silicon solar cell with $10 \times 10 \mathrm{Cm}^{2}$ is used. and the test results before and after the normalization process are given. An intelligent module is added in the block diagram to normalize the measured solar cell characteristics data in dark mode to be presented in the STC condition form. An examination of the implemented LabVIEW model is applied and the results shows a compatibility between the test results presented directly on Oscilloscope monitor with other presented on the developed LabVIEW model front panel.

\section{REFERENCES}

[1] F. Almonacid, C. Rus, L. Hontoria, M. Fuentes, G. Nofuentes, "Characterisation of Sicrystalline PV modules by artificial neural networks", Renewable Energy 34 (2009) 941949

[2] Mellit, M. Benghanem, S.A. Kalogirou, "Modeling and simulation of a stand-alone photovoltaic system using an adaptive artificial neural network: Proposition for a new sizing 
procedure", ScienceDirect, Elsevier, Renewable Energy 32 (2007) 285-313

[3] Ausias Garrigosa, Jose' M. Blanesa, Jose' A. Carrascoa, Juan B. Ejeab, "Real time estimation of photovoltaic modules characteristics and its application to maximum power point operation", Renewable Energy'32 (2007) 1059 1076

[4] Kenji Kobayashi, Ichiro Takano, Yoshio Sawada, "A study of a two stage maximum power point tracking control of a photovoltaic system under partially shaded insolation conditions", Solar Energy Materials \& Solar Cells 90 (2006) 2975-2988

[5] Yoshihiro HISHIKAWA, Sanekazu IGARI and Hiroshi KATO, "Calibration and Measurement of Solar Cells and Modules by the Solar Simulator Method in Japan", 3rd World Conference on Photovoltaic Energy Conversion May 11-18, 2003 Osaka, Japan

[6] J. Thongpron, S. Lohapetch and K. Kirtikara, "Static Parameters of Solar Cells Determined from Solar Simulators Using Quartz Tungsten Halogen Lamps and Super Bright Light Emitting Diodes", 1-4244-0016-3/06/\$20.00 C2006 IEEE

[7] Daniel Koster, Frank Minette, Oliver O'nagy, "Cell Technology Independent I-V Curve Measurement of PV. Modules under Real Operating Conditions", http://www.crte.lu/mmp/ online/website/function/documentation/file_740 0/2006_crte-iv_curve_measurement-pv-sec.pdf
[8] Ensign Benson W. Lo, USNR, Ron Phelps, Sherif Michael, "Evaluation and Testing of the Solar Cell Measurement System Onboard the Naval Postgraduate School Satellite NPSAT1", AIAA 2004-3267

[9] Yan-Fang Li, Saul Harari, Hong Wong, and Vikram Kapila, "Matlab-Based Graphical User Interface Development for Basic Stamp 2 Microcontroller Projects", This work was supported in part by the National Science Foundation under an RET Site Grant 0227479 and the NASA/NY Space Grant Consortium under Grant 39555-6519.

[10] M.G. Guvench, C. Gurcan, K. Durgin and D. MacDonald, "Solar Simulator and I-V Measurement System For Large Area Solar Cell Testing", Proceedings of the 2004 American Society for Engineering Education Annual Conference \& Exposition Copyright @ 2004.

[11] Jun Koyanagi and Kosuke Kurokawa, "A Fundamental Experiment of Solar Cells I-V Characteristics Measurement using LED Solar Simulator", Renewable Energy 2006 Proceedings

[12] Dark Forward Electrical Test Techniques Developed for Large-Area Photovoltaic Arrays, http://www.grc. nasa.gov/WWW/RT/RT1997/ 6000/6920kerslake1.htm

[13] N. Forero, J. Herna'ndez, G. Gordillo, "Development of a monitoring system for a PV solar plant", Energy Conversion and Management 47 (2006) 2329-2336

[14] PVCDROM, http://pvedrom.pveducation.org/main. html 